\title{
Relative Influence of Diversified Factors on the Living Standard of Farmers in Pakistan: A Multivariate Analysis
}

\author{
Adnan Rayit1*, Qiao Zhang1*, Ke Wang1, Muhammad Naeem², Muhammad Sajid Mehmood ${ }^{3}$ \\ ${ }^{1}$ Agricultural Information Institute, Chinese Academy of Agricultural Sciences, Beijing, China \\ ${ }^{2}$ Institute of Apicultural Research, Chinese Academy of Agricultural Sciences, Beijing, China \\ ${ }^{3}$ College of Urban and Environmental Sciences, Northwest University, Xi'an, China \\ Email: *adnanrayit@yahoo.com, *zhangqiao@caas.cn
}

How to cite this paper: Rayit, A., Zhang, Q., Wang, K., Naeem, M. and Mehmood, M.S. (2019) Relative Influence of Diversified Factors on the Living Standard of Farmers in Pakistan: A Multivariate Analysis. Open Journal of Social Sciences, 7, 367-382. https://doi.org/10.4236/jss.2019.78027

Received: July 18, 2019

Accepted: August 26, 2019

Published: August 29, 2019

Copyright $\odot 2019$ by author(s) and Scientific Research Publishing Inc. This work is licensed under the Creative Commons Attribution International License (CC BY 4.0).

http://creativecommons.org/licenses/by/4.0/

(c) (i) Open Access

\begin{abstract}
For effective management of agricultural policies, the determination of current status and impact of multiple factors on the livelihood of farmers is very important. In present study, multivariate technique analysis, Detrended Correspondence Analysis (DCA) and Canonical Correspondence Analysis (CCA) were used to visualize the impact and estimate the influence of these factors on the earning of farmers. Therefore, 400 farmers were selected from 20 villages in Sundry district of Punjab Province in Pakistan. The results indicated that four major clusters of villages on the basis of the information collected during the survey. CCA indicates that farmers having middle age with above secondary school education, medium landholding and obtaining information using computer, audio visual aids, wall chalking and television are highly associated with high income of farming communities. Cultivation of major crops encircles wheat, rice, cotton, sugarcane, maize, significantly improving the living standard of the farming community rather than fruits and vegetables. Hence, it is recommended that all stakeholders, electronic media especially agricultural department and television should effectively perform their role with innovative strategies regarding agricultural crops to the educated middle age farmers for sustainable livelihood.
\end{abstract}

\section{Keywords}

Agricultural Information, Sustainable Livelihood, Farming Community, ICTs, Pakistan

\section{Introduction}

Out of 7.6 billion inhabitants, 208 million reside in Pakistan [1] which is $6^{\text {th }}$ 
largest world population [2] from which $60.5 \%$ belong to rural areas [1]. Whereas, about $58.7 \%$ literacy rate of the country entails $70 \%$ and $48 \%$ of male and female respectively [1]. However, $70 \%$ of the population are mobile users [3]. From overall area of Pakistan, 21.2 million hectare of land [4] is considered as cultivated land; likewise, Pakistan having world contiguous irrigation system [5] [6], two principal cropping seasons in the country such as Kharif (Feb./Mar. to Aug./Sep.) and Rabi (Oct./Dec. to Mar./Apr.) seasons starts and ends respectively. Similarly, four weathers exist in Pakistan namely winter, spring, summer, autumn. In addition, Pakistan has vast fertile agricultural land, rich natural resources and account more than 19\% in the state GDP by agricultural sector. From this agriculture' share of GDP, 17.76 and $11.76 \%$ contribute to Pakistan's exports and imports of agriculture commodities, respectively [7]. Moreover, from the global ranking of agricultural products, Pakistan considered 3rd, 4th, 5th, 6th, 7th, 8th, 9th, and 11th largest date palm and rice exporter, mango and dates producer, also mango exporter, orange, cotton, sugarcane, wheat, beef meat and veal producer in the world respectively. Despite all above mentioned facts, most of the land in Pakistan still exist barren hitherto; likewise, productivity of agricultural commodities is still not only up to the desired level but also having huge potential to enhance agricultural yield from the rural areas [8]. The notion of the term "standard" seems quite clear at a first glimpse: nevertheless, upon closer attention one finds that it's a firm level of accomplishment or execution [9], whereas, living standard of community can be restrained into material and non-material living standard respectively, in which material living standard refers to our access to corporeal possessions and amenities or conveniences [10]. Different states of the world provide diversified living standards to their community; it's very high in advanced countries like UK, USA, Canada and the called affluent societies. On the other side, developing countries seem China, India, Pakistan, Burma, etc., having extremely low living standard [11] [12].

Chief prosperity of the state mainly depends upon the agricultural sector and farmers have gained the status of backbone in the progress of the country [8] [13]. Innumerable agricultural policies have been formulated with the time for improving the living standard of farmers [14] [15]. However, for the successful implementation of these strategies and to enhance the production from agricultural sector, current livelihood status of farming community is vital to know [16]. For better living standard, we considered here as a good education, size of land for agriculture production, income of the farmers, productivity as well as use of modern information resources. Here, a research has been conducted to estimate the current status of farmers and to determine the diverse types of factors which can influence on their livelihood.

Innovative agricultural information can contribute significantly to farmers livelihood [17]. These relevant, timely and adequate sets of information may influence and enhance the agricultural crops or livestock's productivity in addition with maximum utilization and conservation of natural resources [18] [19]. Major key factor influencing the uptake of agricultural innovation is the revela- 
tion of farmers to information [20]. In eastern Uganda nearly $80 \%$ of the rural community appear to have cellphone and radio facility [21].

In agricultural context, information and communication technology (ICT) can be evaluated sketchily under two heads: 1 ) direct contribution to agricultural productivity as direct tool, 2) empower farming community by educating towards quality decisions having positive impact and analogous activities that are conducted as an indirect tool [22]. For making direct share in agricultural productivity information and communication technologies usage extensively whereas; precision farming, popular in developing countries like Pakistan. Remote sensing using satellite technologies, Geographical Information System (GIS) are used to enhance agricultural productivity [23]. One of the strongest reliance on agricultural information exchange between farming community is recognized as agricultural extension [24].

Information and Communication Technologies (ICTs) in agriculture acknowledged in the current era is e-agriculture [25]. In rural domain, it involves the conceptualization, development, design, evaluation and application of innovative ways to use ICTs with a prime focus on agriculture [26]. Its emerging field having prime focus on enhancing agricultural productivity and develop farming community through improved information and communication processes. Whereas, key components of e-agriculture include provision of standards, norms, methodologies and tools as well as progress of individual and organizational capacities [27]. Moreover, ICTs devices include network (GPS, GIS, Remote Sensing), services (Internet/broadband based) and applications (Radio, TV, Mobile, Telephone etc.) [28]. For determining the influence of ICT to economic growth, core question is concerning to the description of ICT [29]. Therefore, ICTs in current study were divided into three major groups namely very old ICTs consist of using technologies for decades and farmer's interaction i.e. newspaper, article, tome, portrait, artwork, surrounded markets (neighbor, friend, colleague) and plays; old ICTs involve TV, FM radio, handset, audio and video recorded cassettes, transparencies/slides, and movie; Last group namely modern ICTs comprises face to face audio or video connections like conference, cell phone, internet, and computer satellite etc. [30].

Above all stated information and communication technologies has reshapes our diurnal lives, obscuring the edge among home-grown and the globe, in spite of promoting access to knowledge-based information and disseminating ideas and ethics [31]. In addition, ICTs has modified the people communication mode and the way wherein they build their social systems [32]. Instead of numerous studies, the evidence of information and communication technologies influence to economic growth in developing countries is still scarce [29]. There is dreadful need of the current era for Pakistan to enhance accumulative agricultural productivity by innovative technologies through optimum utilization of their land \& resources along farmers' sustainable livelihood. Furthermore, to strengthen and empower agricultural sector, ICT exposed the ability to perform efficiently [33].

It would be predicted that the outcomes of research study provide the strong 
basis to under diversified factors for enhancing and sustainable livelihood of farming community in the area. It would also provide the portrait which factors relatively influence the livelihood of farmers as compared to other one along their significance level. Moreover, it also provides the recommendation for improving the living standard of the farming community by influencing expanded factors.

Prime objective of the research study is to analyze the relative influence of diverse factors on the living standard of the farming community; whereas, explicit objectives includes 1) to explore the multiple factors of the farmers; 2) to analyze the relative influence on diverse factors; 3 ) to differentiate factors influencing livelihood of farming community in Pakistan.

\section{Material and Methods}

Material and methods are basically the progression of logical planning for conducting a particular research [25] [34]. Additionally, it elucidates in the scholar study by association among phenomena and level of understanding [35] [36] [37]. The space of the study is vital in shaping what category of information is mandatory and what users are being targeted [38]. Here, Detrended Correspondence Analysis (DCA) and Canonical Correspondence Analysis (CCA) used by researcher to investigate the relative influence of diversified factors on the living standard of the farmers. Furthermore, "Vegan" package provides tools for descriptive community ecology and it has prime function of diversity analysis, community ordination and dissimilarity analysis [39] [40].

\subsection{Population, Sampling and Site Diversification}

Present study was conducted in Pakistan; sovereign country of the South Asia and it lies one of the most strategic location in the world [41], having latitude 28.186385; longitude 67.695237. Total land area of the state is 79.6 million hectare [42]. Rural farming community in Punjab province of Pakistan was purposively selected as population of the study on behalf of strong ground realities including largest population size which is more than 110 million [1], major agricultural contribution in State's GDP, diversity of agro-ecological zones as well farm products in the area [43].

The designated province has alienated into 36 districts on administrative basis [44], from which 5 were selected randomly as shown in Figure 1.

Here, district Dera Ghazi Khan and Muzaffargarh are considered in southern part of the province, while Sargodha in center and remaining two districts are considered in Potohar Platue region [45]. Therefore, diversity of the area and samples were selected within limited time and resources availability. However, 20 household respondents of a village represent 1 site and 4 sites selected from each district of two from each tehsil.

From each selected district 2 sub districts (tehsil) were selected by using simple random sampling technique. This study focuses on group of 20 household farmers from one village multiply by 2 in a selected tehsil randomly to make a 
sample size of 400 . Hence, 20 villages were selected from 5 districts as a sample of the research study. The lottery method of simple random sampling technique was used to explain the sampling technique. Firstly, names of household representative at the village level were written on a piece of paper. Secondly, these households were assigned letter (A-Z). Thirdly, entire samples were folded and mixed in a shopping bag, out of which 20 were selected. Finally, contacted the selected household respondents and made an appointment for conducting interviews. To justify the sample size, it was found by many researchers claim that "20 - 30" in depth interviews are necessary to uncover 90-95\% of all customer needs for the product categories studied [7] [46].

For further clarification a total of two villages from 10 tehsil of 5 districts were selected with sample size of 400 respondents at 20 household surveys in the Punjab province of Pakistan. The flow chart in Figure 2 highlights the data collection and sample size from the area.

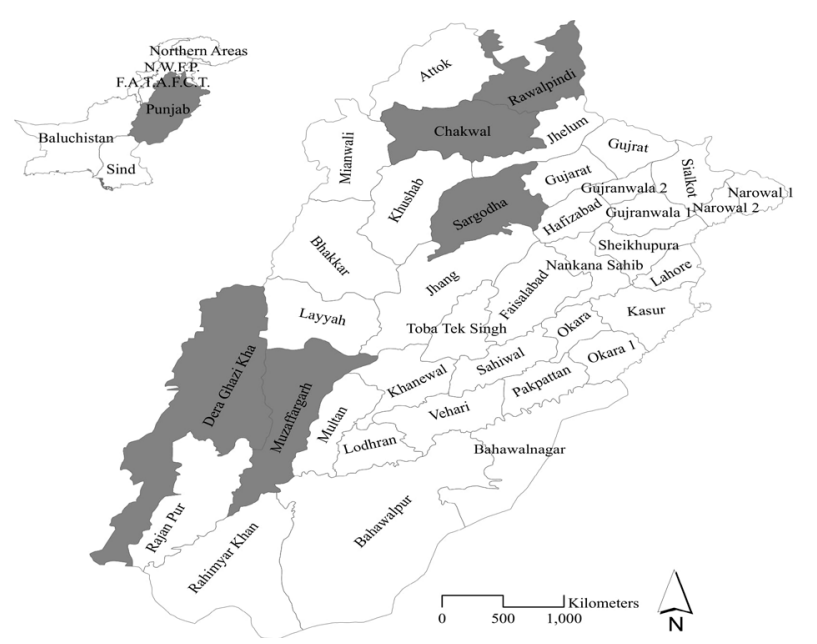

Figure 1. Data collection sites from selected districts (highlighted) in Punjab province of Pakistan.

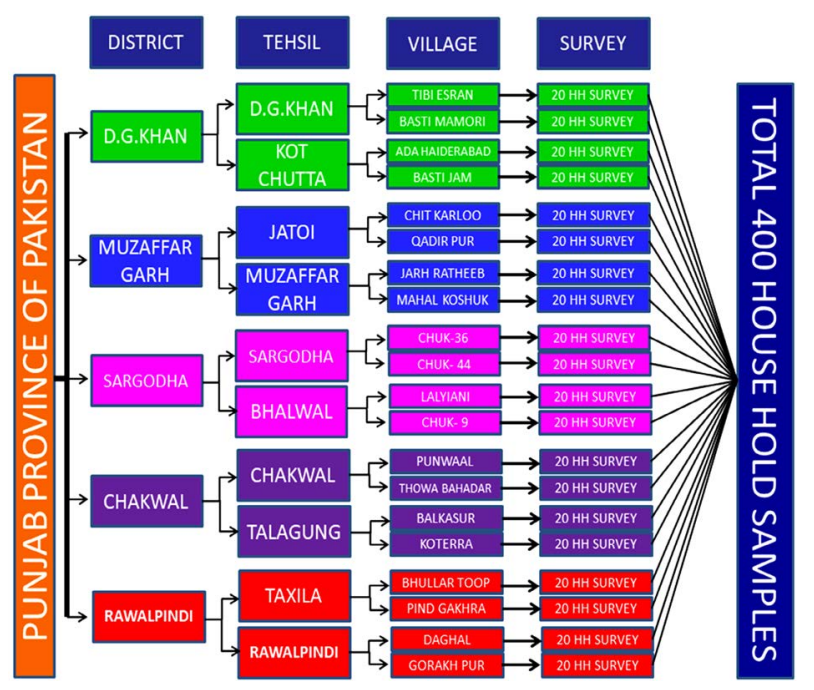

Figure 2. Flow chart for data collection sites from 20 different villages. 


\subsection{Data Collection Procedure and Interviewing}

The contemporary research strongly based on data collection and interviewing the respondents is the chief footstep for eminence exploration [37] [47].

\subsubsection{Design of the Interview Schedule}

Researchers developed validated and pre-tested interview schedule in English and consulted with experts. The complete questionnaire contained three different groups, 1) demographic questions including age, education, size of landholding and farm income, 2) agricultural crops and livestock information, 3) having 3 broader sets of information and communication technologies includes Very Old ICTs, Old ICTs and Modern ICTs.

\subsubsection{Interviewing}

Researcher conducted interviews from all the respondents personally (face to face) by approaching at their doorstep of farm, home or working place but keeping in view the educational level of the farmers; questions were asked in their desired (local/national) language for acquiring quality information with optimum accuracy.

\subsubsection{Tools}

Global Positioning System (GPS) version German $\mathrm{eTarex}^{\mathrm{R}} 201 \mathrm{x}$ device used for taking coordinates of each data collection site.

\subsection{Data Analysis and Multivariate Technique}

Microsoft office $v 2016$ used for data entry and frequencies, sum, average, percentages were calculated on MS-Excel in addition ArcGIS $v 10.0$ for making maps to highpoint the location of the area. For the analysis of distribution of diversified factor and their influence on income Detrended Correspondence Analysis (DCA) and Canonical Correspondence Analysis (CCA) were used to within "vegan" package of R 3.3.1. In addition, DCA and CCA were used to investigate the livelihood status of the farming community and distribution of 20 villages as sampling sites with regard to their three sets of variables namely Socio-demographic, Farm product and ICTs were used to study their effect on the income of the farmers.

\subsection{The Following Set of Variables Was Used under Queries}

\subsubsection{Socio-Economic Variables}

In general, from all sites, income, age, education, and landholding status of the household farming community painstaking but for more accurateness, variables were supplementary classified into low, average, or high income; young, middle and old age; illiterate, primary, middle, secondary school certificate and above secondary school level of education respectively.

\subsubsection{Farm Product Variables}

All types of crops, vegetables and fruits production from each site were the 
second set of variables. Moreover, livestock accumulative information also encompassed under this parameter.

\subsubsection{ICTs Variables}

These customary variables were classified into 3 major categories including very old ICTs, old ICTs and modern ICTs. For better conception and vibrant portrait regarding ICTs characterized furtherly; very old ICTs comprises family member, friend/colleague/relative/neighbor, local leader/ key informant, progressive farmer/grower, middle men, printed material, wall chackling, telephone and self-experience respectively; old ICTs entails namely agricultural personnel, research institution, cooperative society/NGOs, input supplier/insecticide/pesticide, tv, radio, audio/video cassettes respectively and modern ICTs consist of agricultural helpline, mobile and internet/computer respectively.

\section{Results and Discussion}

\subsection{DCA for Sites Only}

A DCA ordination plot Figure 3 for sites reveal the four major groups (cluster)of collection sites of the sampling with eigenvalues of first two DCA axes are 0.075 and 0.043 . Within the DCA space, coloured diamonds along the village names were used to differentiate the clusters. Cluster 1 has four villages (20\%; colour lime; i.e. Qadir Pur, Chit Karlo, JarrhRatheeb and Mahal Koshuk), with their position shown at the lower left side of the DCA space. Cluster 2 is the smallest group of villages (2) with $10 \%$ contribution (colour purple). These villages are PindGakhra and Chak-9 Shumali Model Village, which are located at the lower right side. The largest cluster (Cluster 3 ) is located at the centre to the right side with $40 \%$ contribution. This cluster comprises eight villages, namely, Koterra, Thowa Bahadur, Bhullar Toop, Balkasur, Chak-44 Shumali, Punwaal, GorakhPur and Daghal (colour red). Cluster 4 has scattered villages (30\%) within the DCA space and is located at the top left to the bottom centre (colour

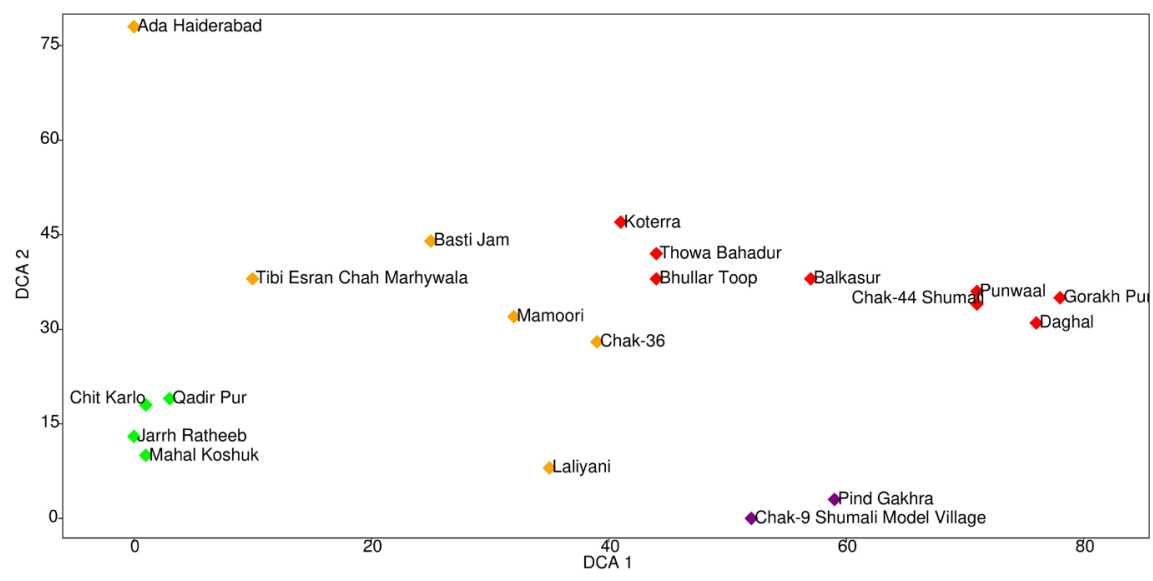

Figure 3. DCA for the distribution of 20 villages in DCA space based on types of information obtained from villagers. Filled diamond symbols with the same colour, green, purple, red and orange, represent cluster 1,2, 3 and 4 respectively. 
orange). This cluster consists of Ada Haiderabad, Basti Jam, TibiEsranChahMarhywala, Mamoori, Chak-36 and Laliyani.

\subsection{Effect of Different Variables on the Income of Farmers}

For such analysis, we used CCA analysis with three sets of variables including respondent age and education level, farm products and different types of ICTs. In Figures 4-6, CCA space represents the distribution of villages different than DCA space. The results are presented in an ordination diagram in which the blue dot represents the entire income variables in Figures 4-6. Those without blue dots on their names at the end of the line show the other variables that were considered in this study. A small angle between lines represents a high correlation between variables. The directions of lines symbolise a positive or negative correlation. Filled blue circles represent the three income levels in the CCA space in different locations. Other factors are highlighted with their names

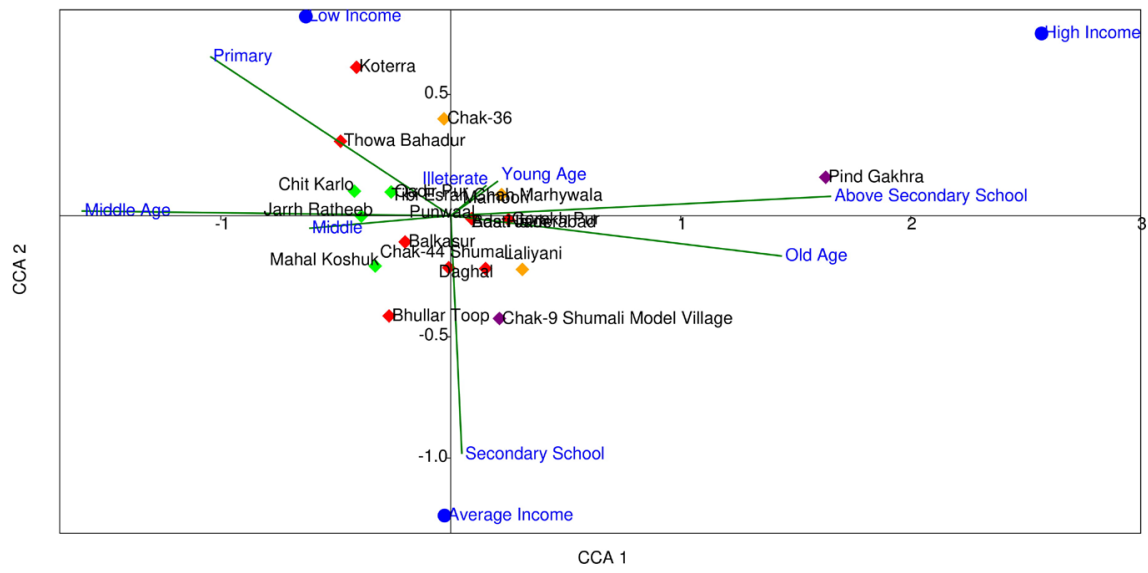

Figure 4. Effect of age and education levels (with green lines) on farmers' income (with blue filled circles) in CCA. Filled diamond symbols with the same colour, green, purple, red and orange, represent cluster 1, 2, 3 and 4 respectively.

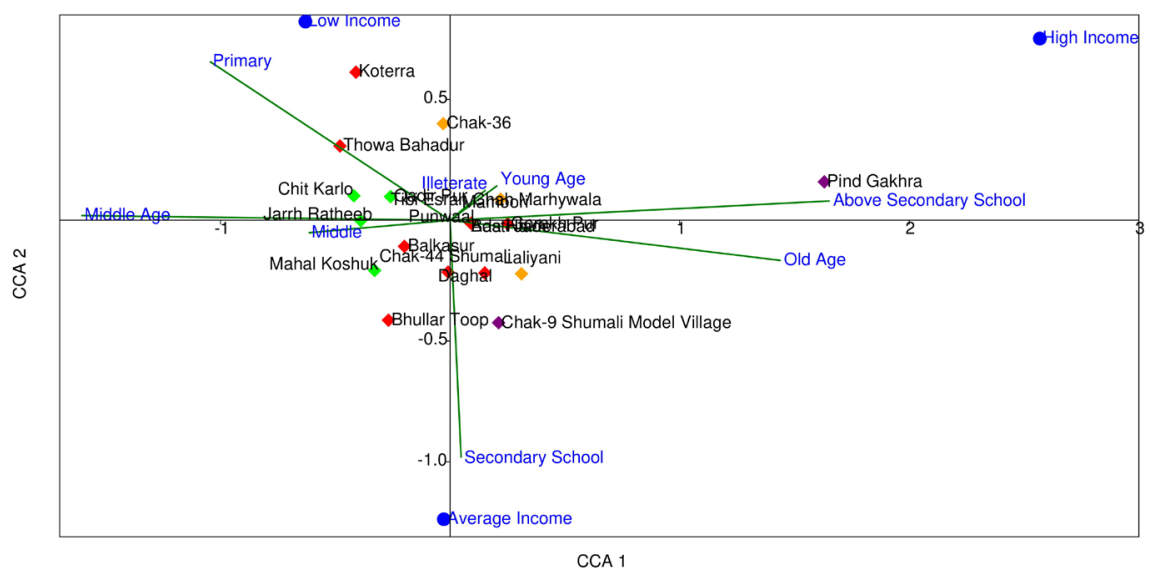

Figure 5. Effect of farms products and landholdings (with green lines) on farmers' income (with blue filled circles) in CCA. Filled diamond symbols with the same colour, green, purple, red and orange, represent cluster 1,2, 3 and 4 respectively. 


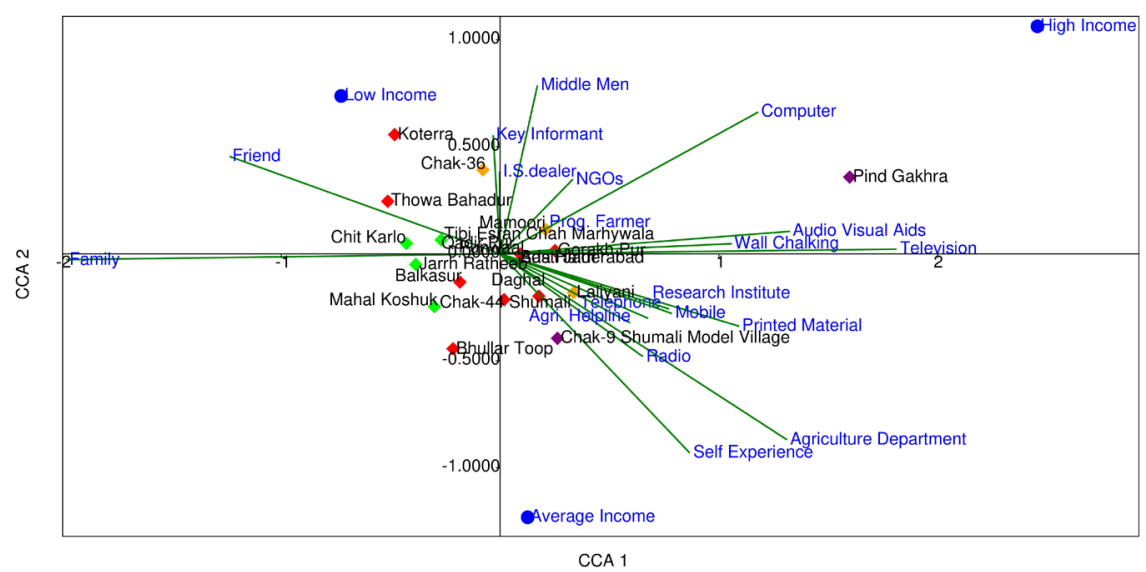

Figure 6. Effect of Information and communication technologies (ICTs) (with green lines) on farmers' income (with blue filled circles) in CCA. Filled diamond symbols with the same colour, green, purple, red and orange, represent cluster 1, 2, 3 and 4 respectively.

among clusters in the aforementioned figures. However, the symbol and colour pattern of clusters at the village level remain similar for all figures in the DCA plot. For analysis, we used CCA with three sets of variables. At the first level, we investigated the effects of age and education level on farmers' income at the village level (cluster). Secondly, we determined the effects of landholding and variety of farm products on farmers' income. Finally, we studied the effects of different types of ICT on farmers' income for improving their living standard. Table 1 showed significant positive correlation and their effect on income of the farmers against diversified variables.

\subsubsection{Effects of Age and Education Level on Farmers' Income}

Figure 4 shows the effects of age and education level on farmers' income. The eigenvalues for the first two axes are 0.12233 (91.67\%) and 0.01111 (8.326). In the CCA space from educational prospective, the variable "above secondary school" is located from the centre to the slightly upper-right direction of axis 1. Secondary school level of education is located at the centre of axis 2 with downward and slightly right directions. These directions are positively associated with "high income" and "average income" from Cluster 2 villages, namely, PindGakhra and Chak-9 Shumali Model Village, respectively. Meanwhile, $75 \%$ of Cluster 1 reported middle level of education, which is slightly scattered from the centre to the middle left of the CCA space. However, two villages from Cluster 3 (i.e. Koterra and Thowa Bahadur) and one village from Cluster 4 (i.e. Chak-36) reported low income level among all villages with the primary level of education. Moreover, the remaining clusters are located near the centre of the CCA space in the scattered position. Age is located more or less near the centre of the plot in Figure 4.

\subsubsection{Effects of Farm Products and Landholding on Farmers' Income}

The CCA also reveals that the second set of variables namely farm products include crops, fruits, vegetables and livestock along with size of landholding in 
Table 1. Effect of diversified factors on income of the farmers.

\begin{tabular}{|c|c|c|c|c|c|}
\hline & Effect of Factors & CCA1 & CCA2 & $\mathbf{r}^{2}$ & $\operatorname{Pr}(>\mathbf{r})$ \\
\hline \multirow{3}{*}{ Age Level } & AY (Young Age) & 0.92704 & 0.37496 & 0.0111 & 0.848 \\
\hline & AM (Middle Age) & -0.9989 & -0.04713 & 0.4157 & $0.015^{*}$ \\
\hline & AO (Old Age) & 0.99996 & -0.00925 & 0.332 & 0.051 \\
\hline \multirow{5}{*}{$\begin{array}{l}\text { Education } \\
\text { Level }\end{array}$} & Illiterate & 0.91007 & 0.41446 & 0.007 & 0.948 \\
\hline & Primary & -0.95602 & 0.2933 & 0.2246 & 0.096 \\
\hline & Middle & -0.99516 & -0.09825 & 0.0628 & 0.576 \\
\hline & Secondary School Certificate & -0.09143 & -0.99581 & 0.155 & 0.247 \\
\hline & Above Secondary School Certificate & 0.99685 & 0.07932 & 0.4474 & $0.014^{*}$ \\
\hline \multirow{3}{*}{ Landholding } & Small Land & 0.98863 & -0.15039 & 0.2521 & 0.102 \\
\hline & Medium Land & -0.99996 & -0.00938 & 0.2888 & $0.056^{*}$ \\
\hline & Large Land & 0.11937 & 0.99285 & 0.1337 & 0.278 \\
\hline \multirow{4}{*}{$\begin{array}{c}\text { Farm } \\
\text { Products }\end{array}$} & Crops & 0.99538 & 0.09602 & 0.6312 & $0.003^{* *}$ \\
\hline & Vegetables & -0.90805 & 0.41886 & 0 & 1 \\
\hline & Fruits & -0.97853 & -0.20609 & 0.181 & 0.183 \\
\hline & Livestock & 0.95497 & -0.2967 & 0.211 & 0.119 \\
\hline \multirow{9}{*}{ Very Old ICTs } & Family & -0.99763 & 0.06877 & 0.6309 & $0.002^{* *}$ \\
\hline & Friend & -0.90976 & 0.41514 & 0.2891 & 0.092 \\
\hline & Key Informant & -0.03167 & 0.9995 & 0.0499 & 0.615 \\
\hline & Progressive Farmer & 0.90377 & 0.42802 & 0.0089 & 0.929 \\
\hline & Middle Men/ Arhati & 0.23826 & 0.9712 & 0.1018 & 0.285 \\
\hline & Printed Material & 0.92964 & -0.36846 & 0.2168 & 0.109 \\
\hline & Wall Chalking & 0.99928 & -0.03794 & 0.1794 & 0.176 \\
\hline & Telephone & 0.88155 & -0.47209 & 0.092 & 0.432 \\
\hline & Self-Experience & 0.64286 & -0.76599 & 0.2749 & 0.103 \\
\hline \multirow{7}{*}{ Old ICTs } & Agricultural Department & 0.79614 & -0.60512 & 0.4184 & $0.008^{* *}$ \\
\hline & Research Institution & 0.92159 & -0.38816 & 0.1103 & 0.393 \\
\hline & Non-Govt. Organization & 0.72733 & 0.68629 & 0.0351 & 0.753 \\
\hline & Input Supply Dealer & 0.01947 & 0.99981 & 0.0238 & 0.716 \\
\hline & Television & 0.99751 & -0.07046 & 0.5265 & $0.003^{* *}$ \\
\hline & Radio & 0.7672 & -0.6414 & 0.1111 & 0.355 \\
\hline & Audio-Visual Aid & 1 & -0.00305 & 0.2812 & 0.088 \\
\hline \multirow{5}{*}{ Modern ICTs } & Agricultural Helpline & 0.84401 & -0.53633 & 0.077 & 0.513 \\
\hline & Cell Phone/Mobile & 0.91448 & -0.40464 & 0.1157 & 0.346 \\
\hline & Computer/Internet & 0.90363 & 0.42831 & 0.2796 & 0.07 \\
\hline & Agricultural Float & 0 & 0 & 0 & 1 \\
\hline & Any Other & 0 & 0 & 0 & 1 \\
\hline
\end{tabular}


Figure 5. The eigenvalues for the first two axis are 0.1663 (90.61\%) and 0.017229 (9.388\%). In CCA space from the farm product prospective, all types of crops are located at the centre towards the upper side of axis 2 in the negative direction. This direction is on the slightly opposite side from that reported in the case of fruit production. Interestingly, vegetable production appears in the centre of the plot, whereas rearing of livestock and its production appears on the CCA space from the centre to the negative direction of both axes in the plot. Landholding of small lands is located at the upper side of livestock production, whereas landholding of large lands is located at the top centre of both axes, which slightly tends towards the left direction in the plot. Medium-sized landholding is located at the central line of axis 1 in the positive direction.

\subsubsection{Effects of ICTs on Farmers' Income}

The CCA analysis concerning the last set of variables including diverse types of ICT influence farmers' income as shown in Figure 6. The eigenvalues for the first two axes are 0.18874 (76.5\%) and 0.057965 (23.5\%). In the CCA space from the ICT prospective, 3 out of 19 ICTs are located at the negative direction of the central axis in the plot, namely, family, friend and key informant. However, all other ICTs are located in the positive direction of both axes of the plot, which is scattered away from the upper side towards the lower side. These ICTs are input supply dealers, middlemen, NGOs, computers, progressive farmers, audio-visual aids, televisions, research institutes, telephones, agricultural helplines, mobile phones, printed materials, radios, agricultural department, and self-experience. The clusters of these villages are more or less in similar locations to those in previous figures.

\subsection{Discussion}

On the basis of DCA, our results indicated four major clusters of villages. Within the DCA space, the villages close to one another showed the presence of similar types of agricultural attributes. Based on the DCA, our findings showed that the group of villages from Clusters 1, 2 and 3 are highly associated with one another because of the presence of similarity in information between the villages (Figure 3). However, Cluster 4 shows contradictory in terms of presence of agricultural information. All the six villages from cluster 4 , do not have shared information between each other. The most dominant attribute is found in Cluster 1, that is, growing of mango trees, which associates their villages with one another. Fruit trees reflect income in Cluster 2. However, Cluster 3 reports moderate association with one another towards information collected from their village's respondents.

On the basis of CCA, farmers with high education level are highly associated with the high-income level of the farming community for improving their living standard (Figure 4). By contrast, low-level income is highly associated with low-level education, which indicates that illiterate farmers have low income and low living standard. Hence, our findings show that an improved level of educa- 
tion might enhance farmers' income, which will ultimately improve their living standard on a sustainable basis.

The major findings of this study show that the types of crops include wheat, cotton, sugarcane, rice and maize. Mangoes are mostly cultivated in the villages of Cluster 1, with livestock production occupying a small landholding area and earning a low level of income. Villages within Cluster 2 have high income from the villages of other clusters by growing fruit trees on a medium-sized land. However, nearly $62 \%$ and $83 \%$ of Clusters 3 and 4 are cultivating vegetables for survival and domestic usage, respectively. These clusters have very low income. Hence, a medium-sized landholding area with cultivation of fruit trees influence farmers' income to improve their living standard (Figure 5).

To investigate the effects of various ICT variables on farmers' income, CCA was applied with consideration of their overstory. Our findings highlight that all types of ICT have positive association with farmers' income and improve their living standard, except for families, friends and key informants, which report low levels of income. The most dominant ICTs include computers, audio-visual aids, televisions, middle men and input supply dealers (Figure 6).

Performing investigations in Pakistan, especially in rural areas of Punjab, is always a difficult task due to people's attitudinal disposition towards the release of information. Mostly, information is considered "sacred" and confidential to release because of the belief that it is a means of evaluating the bearer's worth of tax purposes or political gain of the recipient. Moreover, investigation entails limited resources and time on the part of the researchers.

\section{Conclusion}

Sustainable livelihood of the farmers requires a complete understanding of the various factors and the identification of the most important variables that affect them. Economic growth directly influences the livelihood status of the farming community in Pakistan. In this study, multiple factors were investigated in diversity of sites with their relative influence on income including socio demographic, farm product and ICTs. The findings signpost that young age of the farmers and above secondary school certificate level of education has significant positive correlation with their income from all 20 villages. Cultivation of major crops including wheat, rice, cotton, sugarcane and maize significantly improves the living standard of the farmers through the increase in income except for fruits and vegetables. Moreover, the relative influence regarding ICTs with income showed significantly positive correlation in case of family from very old ICTs; agricultural department and television from old ICTs respectively, whereas, non-significant correlation reported in case of modern ICTs on income. Therefore, it is recommended that all stakeholders, electronic media especially agricultural department and television should effectively perform their role with innovative strategies regarding agricultural crops to the educated middle age farmers for sustainable livelihood. 


\section{Future Direction}

As previously discussed, the study was conducted within a limited geographic area and number of respondents with the aim to investigate the influences of various factors on agricultural development in farming communities. This study identified numerous issues, which could be subjects of further exploration by other researchers, especially in the ICT sector for socioeconomic and sustainable development. Future studies should consider other locations/provinces using case study, focus group and participation approaches with additional respondents to depict farmers' living standard for improvement.

In summary, various research actions have shown that farmers' income, age, education, landholding size, farm products and types of ICT exert significant influences on agricultural development and economic growth for sustainable livelihood. Further investigation should also seek assistance from agriculture-related organisations, such as the Department of Agriculture, NGOs and Agricultural Development Corporation, with regard to strategies to be used in gathering information from farmers.

\section{Conflicts of Interest}

We declare that there is no conflict of interest.

\section{References}

[1] Government of Pakistan (2018) Pakistan Economic Survey, Economic Advisor's Wing Finance Division Islamabad.

[2] Bureau, W.P. (2017) Pakistan Bureau of Statistics. World Population Data Sheet.

[3] PTA Pakistan Telecommunication Authority (PTA) (2017) PTA Quarterly Annual Report, Islamabad.

[4] Okoye, P.U.O. (2017) Pakistan Population and Housing Census.

[5] Government of Punjab (2015) P. Punjab Agricultural Sector Plan 2015.

[6] Salman, B. and Ata, S. (2014) Enabling Agricultural Policies for Benefiting Smallholders in Dairy, Citrus and Mango Industries of Pakistan.

[7] Henschel, T. (2018) Risk Management Practices of Small Farmers.

[8] Lal, R. (2018) Managing Agricultural Soils of Pakistan for Food and Climate. Soil \& Environment, 37, 1-10. https://doi.org/10.25252/SE/18/61527

[9] Personal, M., Archive, R. and Sciences, M. (2013) Personal, Munich, Repec Archive, and Management Sciences. Standard of Living in the European Union, 27 in Standard of Living in European Union.

[10] Anonymous (2017) Living Standards. In: Oxford Big Ideas Economics and Business. Civic and Citizenship, Oxford University Press, Oxford, Vol. 11, 59-70.

[11] Atkinson, A.B. and Marlier, E. (2010) Income and Living Conditions in Europe.

[12] Birčiaková, N., Stávková, J. and Straka, J. (2015) Determinants of Czech Inhabitants' Living Standards. Acta Universitatis Agriculturae et Silviculturae Mendelianae Brunensis, 63, 1839-1845. https://doi.org/10.11118/actaun201563061839

[13] Treinen, S. and Van der Elstraeten, A. (2018) Gender and ICTs; Mainstreaming Gender in the Use of Information and Communication Technologies (ICTs) for 
Agriculture and Rural Development.

[14] Ahmed, M., Khan, M.S. and Iqbal, N. (2017) Wheat Production Trend in Pakistan-A Statistical Analysis. Journal of Agricultural Research, 55, 115-124.

[15] Baloch, M.A. and Thapa, G.B. (2017) Review of the Agricultural Extension Modes and Services with the Focus to Balochistan, Pakistan. Journal of the Saudi Society of Agricultural Sciences, 18, 188-194.

[16] The World Bank (2017) Pakistan Development Update Growth: A Shared Responsibility.

[17] Adio, E.O. (2016) Use of Agricultural Information Sources and Services by Farmers for Improve Productivity in Kwara State, 2016.

[18] Laureys, F. (2016) Use of ICT for Agriculture in GIZ Projects-Status Quo, Opportunities and Challenges.

[19] Liu, Z., Chen, Q. and Xie, H. (2018) Influence of the Farmer's Livelihood Assets on Livelihood Strategies in the Western Mountainous Area, China. Sustainability, 10, 875. https://doi.org/10.3390/su10030875

[20] Olaitan, O.K., Jimoh, F.A. and David, O.O. (2017) Appropriateness of Information and Communication Technologies' (ICTs): A Case Study of Agricultural Information Dissemination in Ogun State, Nigeria. International Journal of Agricultural Extension, 5, 1-9.

[21] Hailu, G., Khan, Z.R., Pittchar, J.O. and Ochatum, N. (2017) Assessing the Radio Programming and Potential Role of Preferred by Farmers Radio Stations to Disseminate Agricultural Technologies in Eastern Uganda. International Journal of Agricultural Extension, 5, 29-42.

[22] Patil, G.I. (2014) Impact of KSAMBS' Free SMS to Farmers on Agricultural Marketing Prices-A Case Study in Karnataka (India). Science Discovery, 1, 28-34. https://doi.org/10.11648/j.sd.20130103.12

[23] Banerjee, A. (2011) The ICT in Agriculture: Bridging Bharat with India. Global Media Journal-Indian Edition, 2, 1-16.

[24] Rehman, F., Muhammad, S., Ashraf, I., Mahmood, K.C., Ruby, T., Bib, I., Ch, K.M., Ruby, T. and Bibi, I. (2013) Effect of Farmers' Socioeconomic Characteristics on Access to Agricultural Information: Empirical Evidence from Pakistan. Journal of Animal and Plant Sciences, 23, 324-329.

[25] Li, X. (2017) Innovation Process in Research and Development Service Firms: The Case of the UK.

[26] Copriady, J. (2015) Self-Motivation as a Mediator for Teachers' Readiness in Applying ICT in Teaching and Learning. In: Proceedings of the Social and Behavioral Sciences, Elsevier, Amsterdam, Vol. 176, 699-708. https://doi.org/10.1016/j.sbspro.2015.01.529

[27] Janssen, S.J.C., Porter, C.H., Moore, A.D., Athanasiadis, I.N., Foster, I., Jones, J.W. and Antle, J.M. (2017) Towards a New Generation of Agricultural System Data, Models and Knowledge Products: Information and Communication Technology. Agricultural Systems, 155, 200-212. https://doi.org/10.1016/j.agsy.2016.09.017

[28] Cynthia, N. (2017) Access and Use of Information and Communication Technologies by Extension Worker in Anambra State Agricultural Development Program, Nigeria. Journal of Agricultural Extension, 21, 80-94.

[29] Farhadi, M., Ismail, R. and Fooladi, M. (2012) Information and Communication Technology Use and Economic Growth. PLOS ONE, 7, e48903.

https://doi.org/10.1371/journal.pone.0048903 
[30] Lashgarara, F., Mohammadi, R. and Najafabadi, M.O. (2011) Identifying Appropriate Information and Communication Technology (ICT) in Improving Marketing of Agricultural Products in Garmsar City, Iran. African Journal of Biotechnology, 10, 11537-11540.

[31] Silva, P., Matos, A.D. and Martinez-Pecino, R. (2017) E-Inclusion: Beyond Individual Socio-Demographic Characteristics. PLOS ONE, 12, e0184545. https://doi.org/10.1371/journal.pone.0184545

[32] Zhou, R., Fong, P.S.W. and Tan, P. (2014) Internet Use and Its Impact on Engagement in Leisure Activities in China. PLoS ONE, 9, e89598. https://doi.org/10.1371/journal.pone.0089598

[33] Jalaee, S. and Zeynali, S. (2013) Impact of Information and Communications Technology on Growth of Agriculture Sector. Asian Journal of Management Sciences and Education, 2, 182-191.

[34] Muhammad, L. (2014) Rural Development Vision and Practices of Culturally Rooted Social Movement Organizations in North-West Pakistan: Implication for Agri. Extension.

[35] Buckley, J., Archibald, T., Hargraves, M. and Trochim, W.M. (2015) Defining and Teaching Evaluative Thinking: Insights from Research on Critical Thinking. American Journal of Evaluation, 36, 375-388. https://doi.org/10.1177/1098214015581706

[36] Mengal, A.A., Mirani, Z.A. and Ali, S. (2015) A Comparative Analysis of Professional Competencies Possessed by Public and Private Agricultural Extension Field Staff in Baluchistan. Pakistan Journal of Agricultural Sciences, 52, 867-871.

[37] Butt, T.M. (2017) Influence of Information Communication Technology (ICTs) on Agricultural Development in the Farming Community of Punjab, Pakistan. China Agriculture University, Beijing.

[38] Ahmad, S., Ashraf, S., Khan, G.A., Ali, S., Ahmed, S. and Iftikhar, M. (2015) Perceived Effectiveness of Information Sources Regarding Improved Practices among Citrus Growers in Punjab, Pakistan. Pakistan Journal of Agricultural Sciences, 52, 861-866.

[39] Oksanen, A.J., Blanchet, F.G., Kindt, R., Legen, P., Minchin, P.R., Hara, R.B.O., Simpson, G.L., Soly, P., Stevens, M.H.H. and Wagner, H. (2018) Package "Vegan" Version 2.5-2.

[40] Liu, J., Ma, K. and Qu, L. (2017) Relative Influence of Sediment Variables on Mangrove Community Assembly in Leizhou Peninsula, China. Marine Pollution Bulletin, 117, 429-435. https://doi.org/10.1016/j.marpolbul.2017.02.003

[41] IFAD (2002) Assessment of Rural Poverty in Asia and the Pacific.

[42] FAO (2011) Irrigation in Southern and Eastern Asia in Figures-AQUASTAT Survey.

[43] Muhammad, S., Lodhi, T.E. and Khan, G.A. (2016) Farmers' Awareness of Agri. Radio and TV Broadcasts and Their Preferences for Different Formats in the Punjab, Pakistan. Bulgarian Journal of Agricultural Science, 22, 513-516.

[44] Statistics, O.F. (2018) Statistics Division, and Ministry of Statistics. Contraceptive Performance Report 2016-2017.

http://www.pbs.gov.pk/sites/default/files//social statistics/contraceptive performan ce reports/Contraceptive Performance Report 2016-17 main report.pdf

[45] Call, A. (2018) Climate-Smart Agriculture in Pakistan. Vol. 62. https://doi.org/10.2134/csa2017.62.0201

[46] Fielding, N.G., Lee, R.M. and Blank, G. (2008) The SAGE Handbook of Online Re- 
search Methods. Sage, Thousand Oaks. https://doi.org/10.4135/9780857020055

[47] Dillis, P.M. (2016) Analysis of Socio-Economic Impact of Comprehensive Agricultural Support Programme on Agrarian Reform Farmers of Sedibeng District Municipality in Gauteng Province South Africa. 